\title{
Education of Overall IT System Design: Locally Situated E-business
}

\author{
Yoshinori Fujio \\ Prefectural University of Kumamoto, Kumamoto, Japan
}

\author{
ujio@pu-kumamoto.ac.jp
}

\begin{abstract}
The paper presents an overall, practicing educational model for designing IT systems for undergraduates. Students are awaked to the target consideration to learn IT in familiar cases, and they are motivated to design IT systems. A unifying theme is established, students execute investigation, research, and designing to achieve that theme. [Locally situated E-business] is taken up in this paper. In order to investigate, to research, and to design the theme, four groups are organized. Each group has its own sub-theme; investigation of business model, designing of client/server system, designing of mobile system, and designing of human interface. As the result of these practices, they are able to obtain a total IT image and an individual designing method. Students can approach the essence of IT through these processes.
\end{abstract}

Keywords: IT system design, E-business, information systems, undergraduate, education

\section{Introduction}

To teach IT designing method, it is vital that students be given incentives to examine and research [The Role of IT in society] and [The Structure of E-commerce and Information systems] and the like in society to gain [A sense of purpose in learning IT].

Next, to find an overall unifying theme and achieve that theme, assign examination, research or planning to different groups. The students by repeated trail and error to solve problems by this examination, research or designing process continue to learn [Actual IT] through direct experience. This paper describes this multi-faceted study method.

\section{Promotion of Locally Situated E-businesses}

As the unifying theme of this paper, I will describe [Locally situated E-businesses]. This theme was decided on after consideration of the following points. The distortions of unified American type economic globalization have begun to be identified as shown by the simultaneous terror incidents in America. Increasing locally based economic activity is necessary to correct this distortion. Connecting IT to local activity, and overlapping it with [A sense of purpose in learning IT] established this theme.

Forming 4 groups of 2 members each advances examination, research and designing. (a)The business

Material published as part of these proceedings, either on-line or in print, is copyrighted by Informing Science. Permission to make digital or paper copy of part or all of these works for personal or classroom use is granted without fee provided that the copies are not made or distributed for profit or commercial advantage AND that copies 1) bear this notice in full and 2) give the full citation on the first page. It is permissible to abstract these works so long as credit is given. To copy in all other cases or to republish or to post on a server or to redistribute to lists requires specific permission from the publisher atpublisher@intormingscience.org model: It was planned by using a business model from the point of view of the customer and the manager, and definite business flow in Use-Case modelling. (b)The client/server system: The bases of the system, a 3 layered structure consisting of a web client, an application server, and a database server, is planned using Windows 2000, JBuilder, and Access, and the business logic and database 
that is that application are designed. (c)The mobile system: A transaction or service system that uses cell phone i-mode (Internet access) is designed. (d)The human interface: Designing the screen and the actual HTML layout and the audio, still and video images contents displayed in HTML.

That the time frame for the research will be lengthy, and proceed in steps was taken into consideration. The first step is the examination of the status of (a), and the completion of the development system for (b), (c) and (d). In the second step the basic design for (a) and the experimental system of (b), (c) and (d) are designed. The third step is the detailed designing for (a), and using (b), (c), and (d) to improve problem points. The research results are documented so that the contents of the previous step can be handed over to the students researching the next step. Also, because information technology is a trial and error process, it is necessary proceed with review and renewal of the previous step's research results.

\section{Business System Evolution}

Papers (Fujio, 1999), (Fujio, 2000) and (Fujio, 2001) have a wholesale business as their object system, and how information, money and price flow between the components is examined, and based on this, points for improvement are brought out Paper (Fujio, 2000) creates a model of the [Organization and information flow (present system)] and the [Voucher flow (present system)] in the present system before computerization. Using this present system as a base, the [Organization and information flow (new system)] and the [Voucher flow (new system)] are created based on a conceptualized new system. Because this new system just switches sales business done manually over to a computerized business it is in the old economy category.

The evolved paper(Fujio, 2001) deals with an information system that does web based E-commerce and comes under the new economy category. Here, the web is used to make the sales and procurement staff

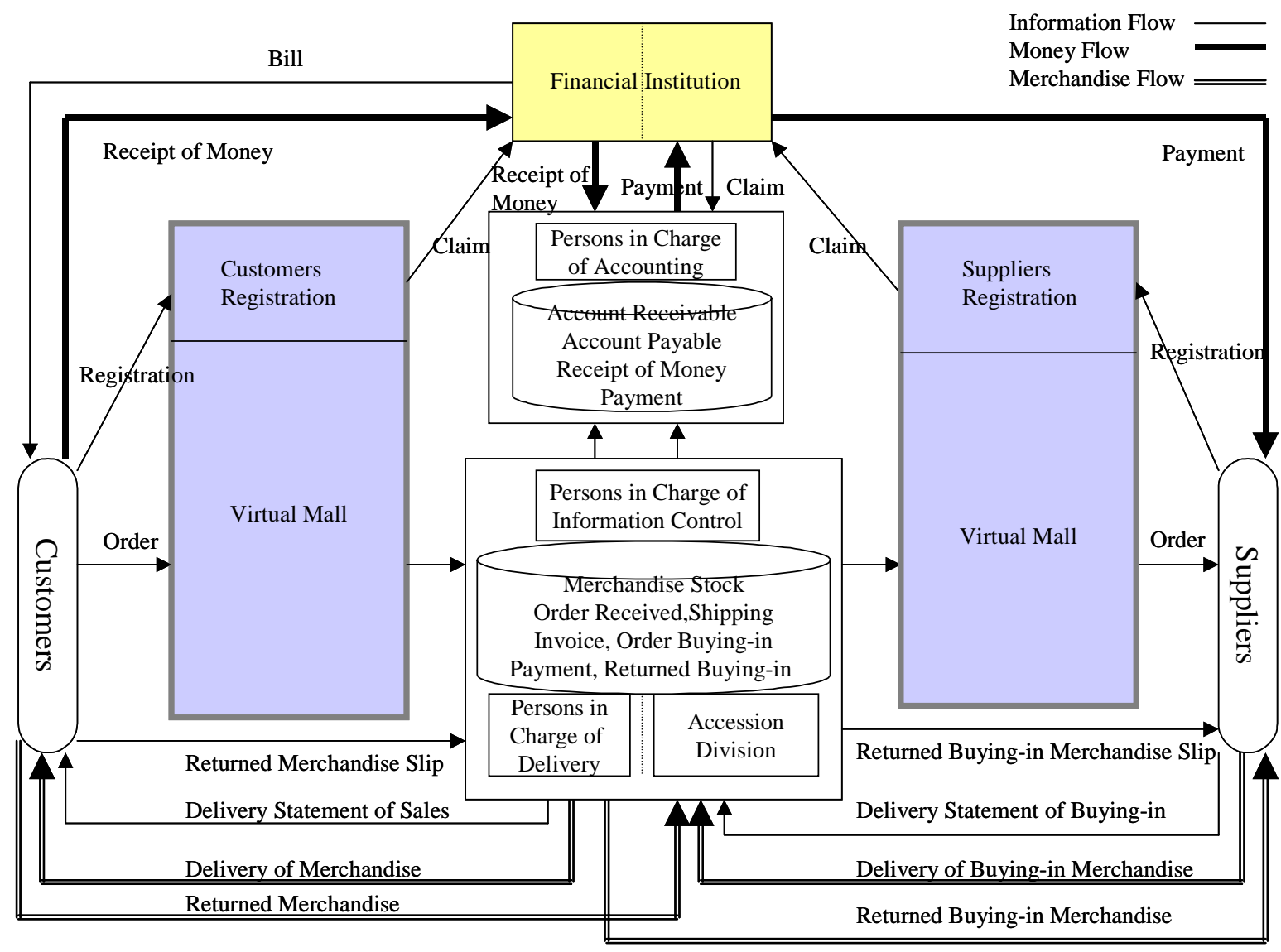

Figure 1: Organization and information flow (E-commerce) 
components virtual. Also, the settlement done between management and the customer (billing and debt), and the settlement done between management and the supplier (billing and payment), may take many forms. But this paper adopts the method of reimbursement at the point in time when the customer orders merchandise with a pre-registered credit card. The [Organization and information flow (E-commerce)] is shown in Figure 1.

\section{The Base System Evolution}

The basic client server system is shown as 3 layers the (presentation layer, logic layer, and the database). Designing the basic system and learning its features and designing elements is vital to this base system designing.

\section{(1)Application}

The method of accessing the database from the application program in the client(Inprise, 1998). Complex input screens can be flexibly designed, but installing the application program in the client is required. (Figure 2)

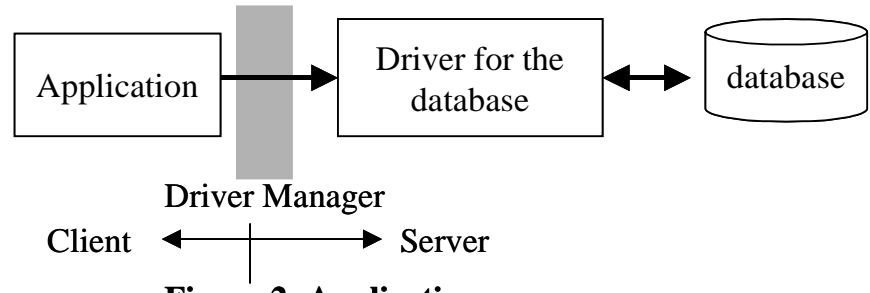

Figure 2: Application

\section{(2) Applet}

The method of using the web browser to access the databases in the server etc. from the client(Inprise, 1998). The applet designates an URL on the client browser, and downloads from the server etc. into the client. The user, using the downloaded applet accesses the database on the server etc. An unspecified number of users can access the database, but if the functionality of the client's browser is limited it may not be able to display the applet. (Figure 3)

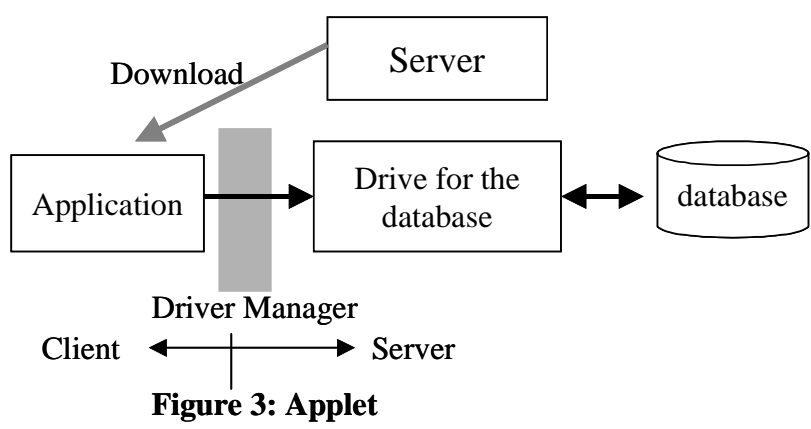

\section{(3) Servlet}

A method of using the web browser to access the databases in the server etc. from the client. This is when an URL is designated in the browser, and only the screen from the servlet in the server is displayed. The user uses this screen to access the database. The ap-

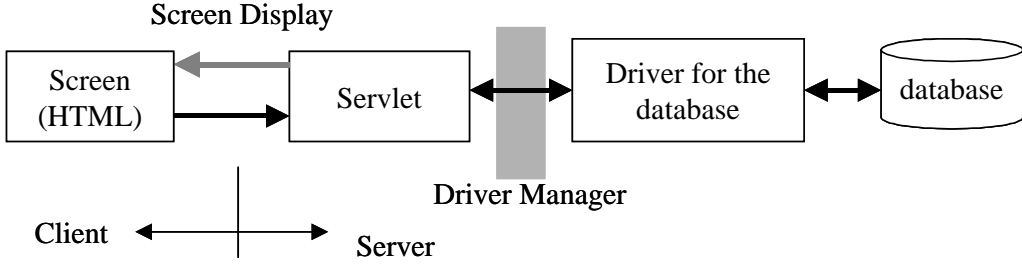

Figure 4: Sevlet plication program doesn't put a load on the client by the server central system in the server, and it is best if the browser can display HTML. But, session administration in the transaction process between the server and the client is necessary(Callaway, 1999)(Pekowsky, 2000). (Figure 4) 


\section{(4)EJB}

This method of using a web browser to access the database is the same as Servlet. What is different is the point that a system can be structured with business components from components that have a large number of combined elements. The EJB server provides system service in the enterprise

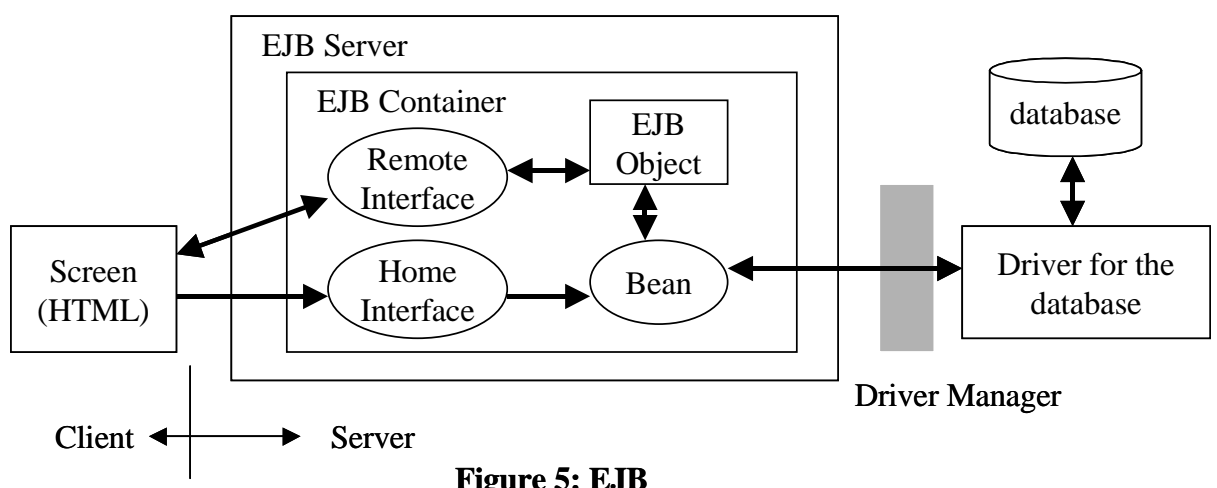

Bean, and administers the container executed by the enterprise Bean. Also, a naming service and a transaction service that can access using JNDI are required. The EJB container connects the enterprise Bean and the EJB server, and administers transactions, security and network sharing(Valesky, 1999)(Inprise, 2000). (Figure 5)

\section{(5)i-mode Application}

The URL is designated using cell phone i-mode (Internet access) and various applications are downloaded from the server(NTTDoCoMo \& Sun Microsystems, 2000)(ASCII, 2001).

A basic system can be planned and acquired from the application in (1), the applet in (2) and the

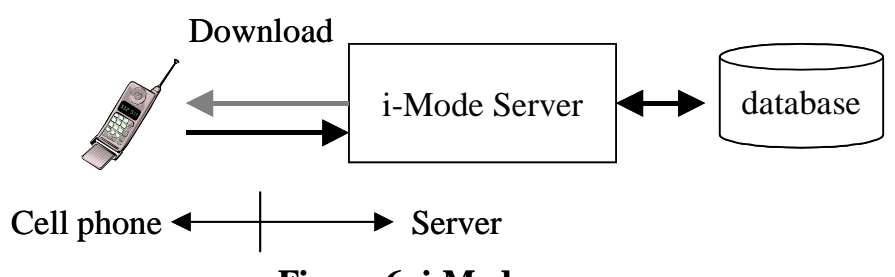

Figure 6: i-Mode servlet in (3) that are the fundamental items for constructing an information system. Also, EJB in (4) and the i-mode application in (5) focus on the actual application. Based on the premise that the basic system using EJB has already been constructed, and with a plan to provide a new business model, process and contents creation, and practical use of models with the application aspect to society as central are visualized. (Figure 6)

\section{Planning Locally Situated E-businesses}

Examples of synthetic systems using the web based E-business in (3), and the system form in (4) shown as (4) EJB and (5) i-mode are shown next. The main hardware that structures the system are the HP NetServer e-800 server, the CPU (Pentium III 733MHz×1), the hard disk $(9.1 \mathrm{~GB} \times 2)$, memory $(128 \mathrm{MB} \times 2)$. The system development software is JBuiler4 Enterprise version (EJB, Imprise Application Server 4.1) and the database (Access). When constructing the system, components using EJB (Enterprise Java Beans) are used and developed, and Imprise Application Server 4.1 using J2EE (Java 2 Platform, Enterprise Edition) is used for testing. Also, i-mode applications are developed using components that use J2ME (Java 2 Mobile Edition). 


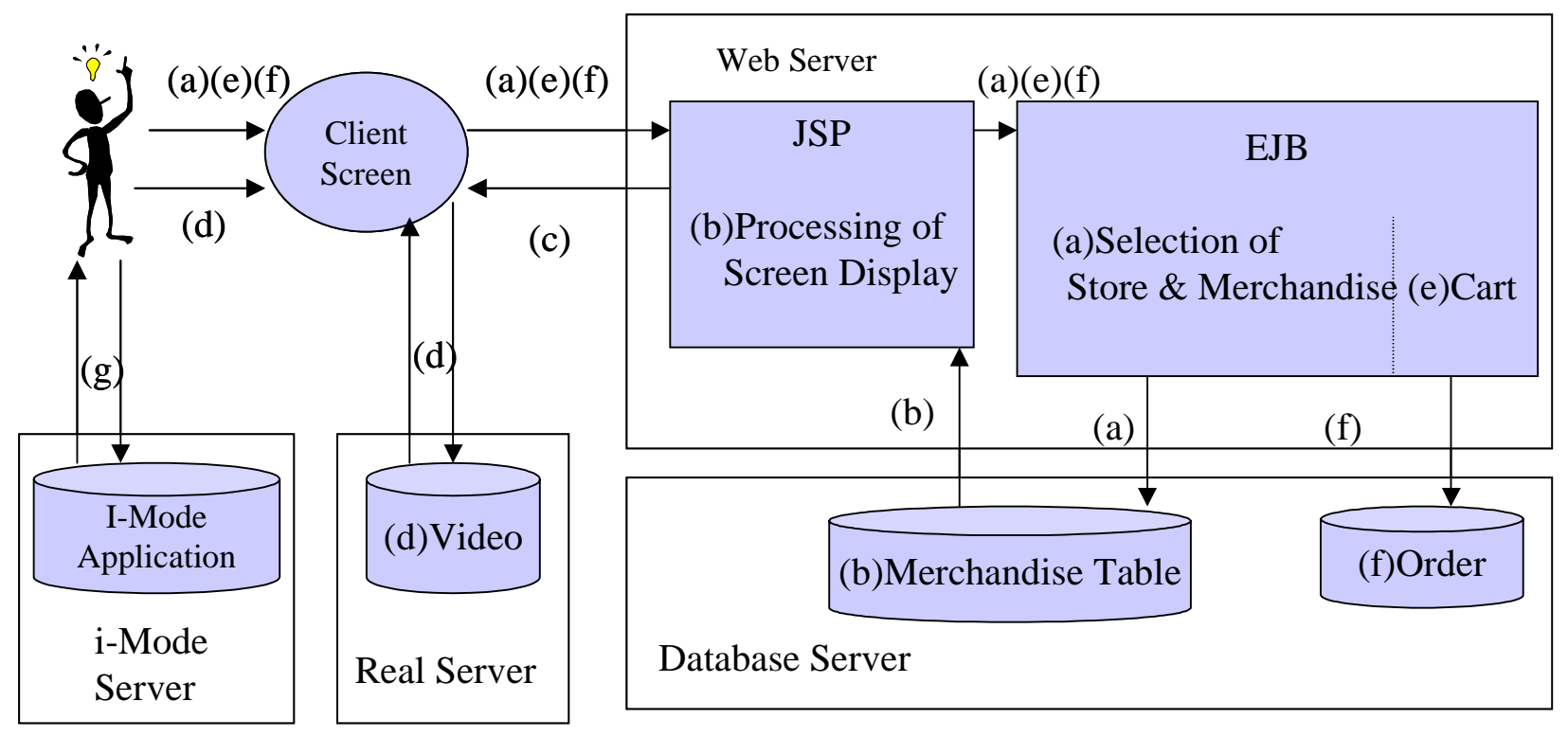

Figure 7: E-Business Outline

The use of E-business systems, especially the merchandise purchasing procedure, is as follows. (Figure 7) First the customer user name and password are input and the virtual mall image is entered. The store to shop at $[(a)]$ in the virtual mall is selected and the selected store merchandise [(c)]based on the merchandise characteristics table of the database [(b)]is displayed. The product content is checked. The detailed content of the merchandise can also be checked by displaying the merchandise table catalog, a still picture displayed as an image, or a video [(d)] on the Real server. Next, the merchandise to be purchased is selected and put in the shopping cart [(e)], and after batch calculation including different stores [(f)] merchandise purchasing is completed.

Local stores and product advertising information can be had on a timely bases using i-mode $[(\mathrm{g})]$. The merchandise table (Figure 8) exists in the database server, and its attributes are merchandise number, merchandise name, price and the still picture attribute and the video attribute. To display the still image, the directory and file name that locate the still image are described in the still image attribute, and in the

Merchandise Table

\begin{tabular}{|c|c|c|c|c|c|c|}
\hline $\begin{array}{l}\text { Merchandise } \\
\text { No. }\end{array}$ & $\begin{array}{l}\text { Merchandise } \\
\text { Name }\end{array}$ & Price & Store No. & Still Picture & & Video \\
\hline 001 & Note Book & 100 & 003 & ../Image/file1.jpg & rtsp://202. & 6.163.60/Archive/re01.rm \\
\hline 002 & Pencil & 150 & 003 & ../Image/file2.jpg & rtsp://202. & 6.163.60/Archive/re02.rm \\
\hline 003 & Dictionary & 1000 & 003 & ../Image/file3.jpg & rtsp://202. & 6.163.60/Archive/re03.rm \\
\hline \multicolumn{4}{|c|}{ Ierchandise Characteristic Table } & \multicolumn{2}{|c|}{ Store Table } & \\
\hline $\begin{array}{l}\text { Merchandise } \\
\text { No. }\end{array}$ & $\begin{array}{l}\text { Customers } \\
\text { Characteristic }\end{array}$ & $\begin{array}{l}\text { Consumption } \\
\text { Characteristic }\end{array}$ & $\begin{array}{l}\text { Time Period } \\
\text { Characteristic }\end{array}$ & Store No. & Store Name & \\
\hline 001 & 5 & 5 & 8 & 001 & Sports Store & \\
\hline 002 & 1 & 3 & 6 & 002 & Fruit Store & \\
\hline 003 & 10 & 2 & 2 & 003 & Stationary Store & \\
\hline
\end{tabular}

Figure 8: Merchandise Database 
video attribute the server, directory and file name that locates the video are described to provide the video(RealNetworks, 2000).

Adding, changing and deleting stores can be done with Access store table. That is, changing merchandise handled by the store is overwriting the content of the store table. The directory and file name that locates the still image that displays the merchandise are described in the merchandise table attribute. Also, in the same way for video, the server directory and file names that locate the video are described in the video attribute.

\section{Conclusion}

At present, as the first step, examination of the present status and the development system are being completed. The students by handling advanced experimental systems gain a sense of purpose, and to achieve the large locally situated goals work hard at lectures and training. The theme of the paper is business model planning, planning the basics of a 3 layered system, application planning of a system that can actually be used by society and doing multi-faceted study. It provides a an opportunity for cooperation between groups to tackle the achievement of a single goal from different points of view, and for unified thinking about the social environment that surrounds information systems. Also, document (use) creation leadership so that planning and research can be continued in the next step is essential.

\section{References}

ASCII Co. (2001). i-Mode Java Programming. Tokyo:ASCII.

Callay, Dustin R.(1999). Inside Servlets. Reading, MA: Addison Wesley.

Fujio, Y. (1999). Information \& Computer Science Education for Departments of Social Science. Administration, Vol.5, No.4, Prefectural University of Kumamoto, Kumamoto, Japan, 39-49.

Fujio, Y. (2000). Information \& Computer Science Education for Departments of Social Science(A Second). Administration,

Vol.6, No.2-3, Prefectural University of Kumamoto, Kumamoto, Japan, 1-12.

Fujio, Y. (2001). Information \& Computer Science Education for Departments of Social Science(A Third Look). Administration, Vol.7, No.1-2, Prefectural University of Kumamoto, Kumamoto, Japan, 209-223.

Inprise Co. (1998). Jbuilder2 Developer's Guide. Tokyo: Inprise.

Inprise Co. (2000). Jbuilder4 Enterprise Application Developer's Guide. Tokyo: Inprise.

NTTDoCoMo, Inc. \& Sun Microsystems, Inc. (2000). I-Mode Java API J2ME wireless SDK User's Guide. Retrieved October

1, 2001 from the World Wide Web http://www.nttdocomo.co.jp/me-user/i/java/tool.html

Pekowsky, L. (2000). Java Server Pages. Reading, MA: Addison Wesley.

RealNetworks, Inc. (2000). RealSystem8 Production Guide. Seattle, WA: RealNetworks.

Valesky, T. (1999). Enterprise JavaBeans. Reading, MA: Addison Wesley.

\section{Biography}

Yoshinori Fujio is a professor at Prefectural University of Kumamoto, where he teaches information system development, software design and web related courses. Professor Fujio has authored papers on the Information \& Computer Science Education, CASE and 4 books on the subject of Information Processing Engineering. 